\title{
DNA SEQUENCE POLYMORPHISMS IN THE GENUS SACCHAROMYCES IV. HOMOEOLOGOUS CHROMOSOMES III OF SACCHAROMYCES BAYANUS, S. CARLSBERGENSIS, AND S. UVARUM
}

\author{
by \\ MOGENS BOHL PEDERSEN
}

Department of Brewing Chemistry, Carlsberg Research Laboratory, Gamle Carlsberg Vej 10, DK-2500 Copenhagen Valby

\begin{abstract}
Keywords: S. cerevisiae, S. inusitatus, S. monacensis, S. pastorianus, bottom fermenting, DNA, hybridization, restriction endonuclease fragment length polymorphisms, HIS4, $L E U 2$, genetic analysis, heterokaryon, karl, recombination, electrophoretic karyotype, OFAGE
\end{abstract}

\begin{abstract}
Single chromosome III transfers have been accomplished from the two species $\mathrm{S}$. bayanus and S. uvarum into genetically marked $\mathbf{S}$. cerevisiae strains. Incompabilities between $\mathbf{S}$. bayanus or $\mathbf{S}$. uvarum, and $\mathbf{S}$. cerevisiae strains may account for the very few chromosome addition lines obtained. The preliminary genetic map for $\mathrm{S}$. bayanus chromosome III is similar to the genetic map for a S. carlsbergensis chromosome III from Danish lager strain BK2208. Recombination is absent between the transferred chromosomes and the auxotrophically marked chromosome from S. cerevisiae in the interval $H I S 4$ to $L E U 2$ but recombination does occur in the interval $L E U 2$ to THR4. The mapped S. bayanus chromosome III carries HIS4 pattern III while the mapped chromosome III from the lager strain contains HIS4 pattern II. Transfer of a chromosome III from S. uvarum to S. cerevisiae has been recognised by restriction endonuclease fragment patterns, OFAGE chromosome separations and molecular hybridization, but a genetic map could not be constructed for an S. uvarum chromosome due to instability of the chromosome addition lines. The hypothesis is put forward that the $S$. carlsbergensis type strain and the lager strains are sibling species and species hybrids both produced by hybridization of an $\mathbf{S}$. cerevisiae top fermenting strain and the bottom fermenting strain $\mathbf{S}$. monacensis. The lager strains and the authentic type strain are designated $\mathbf{S}$. carlsbergensis. From the electrophoretic karyotypes of type strains of Saccharomyces and molecular hybridization patterns it is deduced that $\mathbf{S}$. bayanus, $\mathbf{S}$. inusitatus, $\mathrm{S}$. pastorianus and $\mathrm{S}$. uvarum are closely related but distinct from the battom fermenting strains.
\end{abstract}

\section{INTRODUCTION}

Base composition, DNA-RNA homology, DNA-DNA reassociation kinetics and restriction endonuclease fragment length polymorphisms have proven useful in the taxonomic evaluations of genera and species as well as in the diagnosis of closely related yeast strains $(3,4,15$, $21,23,24,25,26,27,28,30,40)$. For taxonomic as well as breeding purposes the establishment of genetic linkage groups and their assignment to

Abbreviations: OFAGE $=$ Orthogonal field alternation gel electrophoresis; $\mathrm{TBE}=0.089 \mathrm{M}$-Tris-borate, 0.089 M-boric acid, $0.002 \mathrm{M}$-EDTA; SSC $=0.15 \mathrm{M}-\mathrm{NaCl}, 15 \mathrm{mM}-\mathrm{Na}$ citrate. 

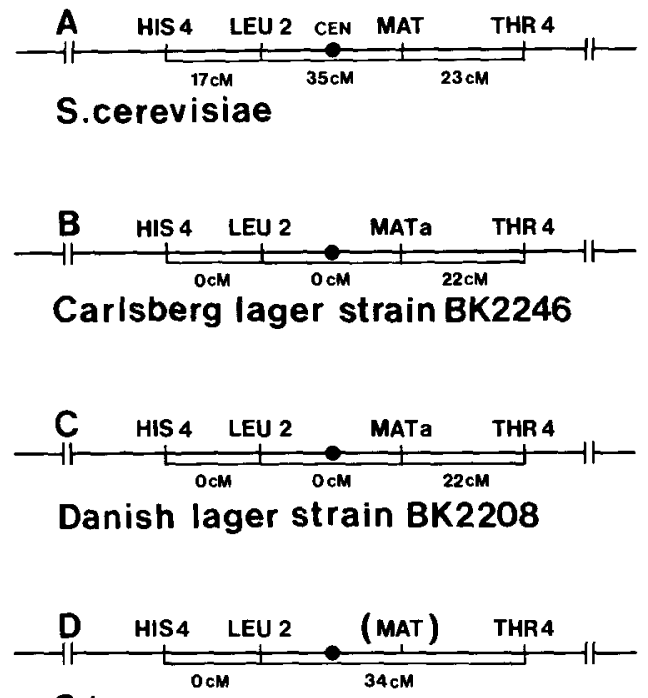

\section{S. bayanus}

cytologically or electrophoretically recognisable chromosomes is desirable. By selectable transfer of a single or a few chromosomes from an
Figure 1. Genetic map of chromosome III from four Saccharomyces strains. The distances in $\mathrm{cM}$ are calculated on the basis of the recombination values between the three prototrophic chromosomes and a standard S. cerevisiae chromosome III carrying the appropriate mating type and auxotrophic markers. Chromosome B according to (21), and C and D to this study. Strains B and $\mathbf{C}$ differ by their $T y$ element patterns. B (Carlsberg lager strain) contains pattern I, while $C$ (Danish lager strain BK2208) contains pattern IIa (27).

uncharacterised yeast strain or species into a well marked genetic strain knowledge of linkage groups and chromosome homology can be established. This has been demonstrated for the Carlsberg lager strain $(20,21)$. By genetic and molecular analyses the lager strain was found to be amphiploid for homoeologous chromosomes apparantly originating from two different species $(21,22)$. In the present study the transfer of chromosome III from Saccharomyces bayanus BK4505, from the Danish lager strain BK2208

Table I. Characteristics of S. bayanus, S. carlsbergensis, S. monacensis, S. pastorianus, and S. uvarum. Restriction fragment patterns of the RDN1, HIS4, LEU2 and Ty genes are according to $(24,27$ and this study). -: Indicates very weak to no hybridization to $T y 1 \mathrm{p} 14$.

\begin{tabular}{llllll}
\hline Strains: & RDNI & HIS4 & LEU2 & Ty & Karyotypes: \\
\hline S. bayanus group: & & & & & \\
S. bayanus CBS380 & III & II+III & IV & - & Figure 2 \\
S. bayanus NCYC374 & III & II+III & IV & - & Figures 2, 6 \\
S. pastorianus ATCC12752 & III & II+III & IV & - & Figure 2 \\
S. pastorianus NCYC392 & III & II+III & IV & - & Figure 2 \\
& & & & & \\
Bottom fermenting yeast group: & III & I+IIa & III+IV & III & Figures 2, 3, 4 \\
S. carrlsbergensis C84-AJL248 & III & I+IIa & III+IV & III & Figure 2 \\
S. carlsbergensis CBS1513 & III & I+IIa & III+IV & III & Figure 2 \\
S. carlsbergensis NCYC396 & III & II & IV & IV & Figure 3, 4 \\
S. monacensis CBS1503 & II & II & III+IV & IIa & Figure 4 \\
Pschorr lager strain BK1101 & II & I+II & III+IV & IIa & Figures 8, 9 \\
Danish lager strain BK2208 & II & I+II & III+IV & II & Figures 3, 4, 9 \\
Tuborg lager strain BK2224 & II & I+II & III+IV & I & Figures 3, 4, 9 \\
Carlsberg lager strain BK2246 & & & & & \\
& & & & & Figure 9 \\
S. uvarum group: & III & III & IV & - & Figure 2 \\
S. inusitatus CBS1546 & III & IIIa & IV & - & Figures 2, 9 \\
S. uvarum C81-1510 (CBS395) & III & III & IV & - &
\end{tabular}


Table II. Characteristics of strains used in the genetic and molecular studies.

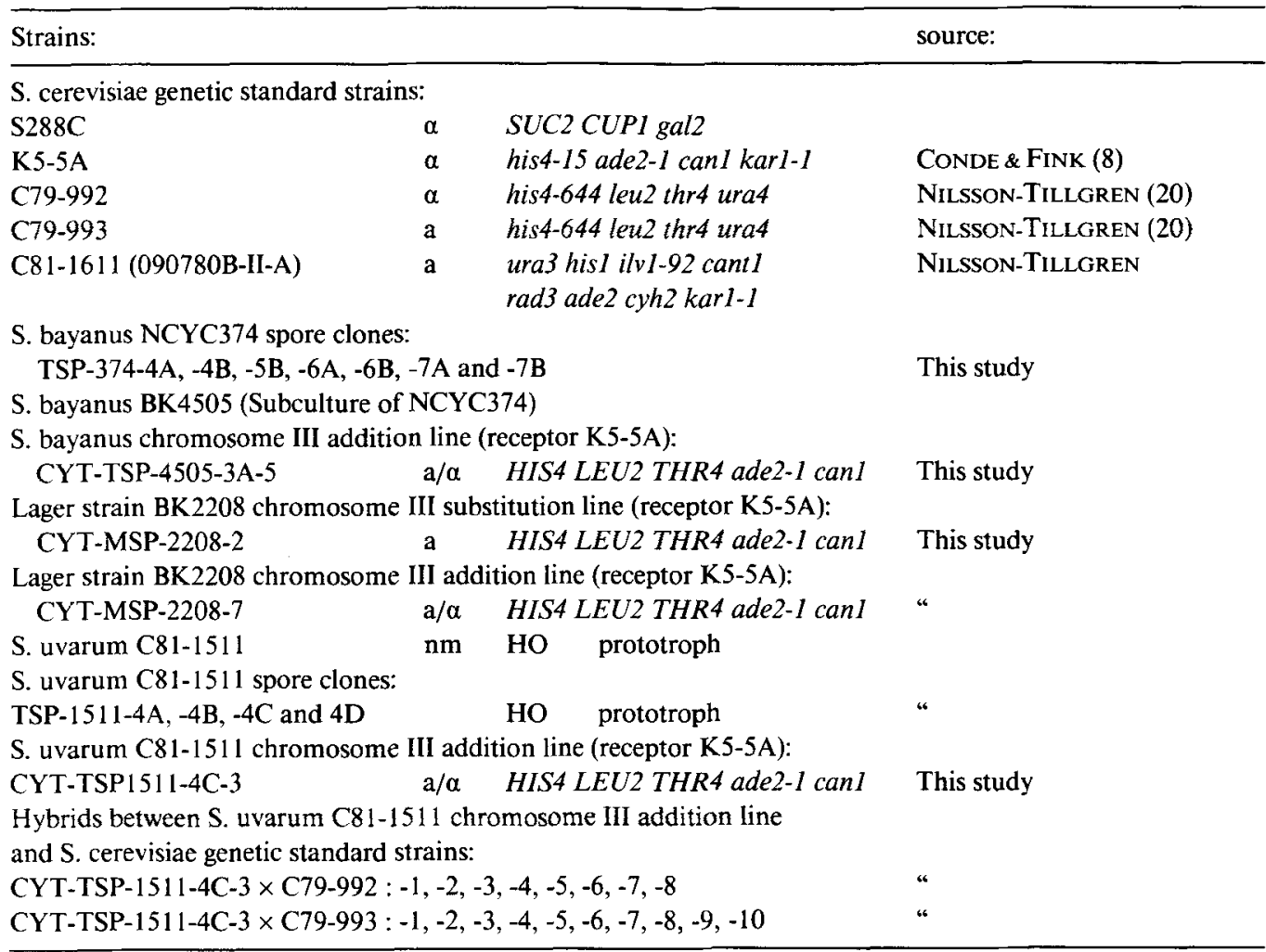

(S. carlsbergensis) and from S. uvarum (C811511) into a Saccharomyces cerevisiae strain with appropiate recessive markers was attempted. Using in the recipient the karl-l gene to prevent karyogamy, appropriate chromosome addition and/or substitution lines are obtained. These are characterised by genetic analysis and for restriction endonuclease fragment patterns of the HIS4 and LEU2 regions. Separation of the chromosomes by orthogonal field alternation gel electrophoresis in conjunction with molecular hybridization of Southern transfers to the chromosome III HIS4 pC503 probe (14) established basic features of the karyotypes of the three species studied. A map of chromosome III with the relevant markers is given in Figure 1.

\section{MATERIALS AND METHODS}

\subsection{Strains and media}

The Saccharomyces species used in the present study are listed in Table I together with their known DNA characteristics. Genetic standard strains and chromosome addition or substitution lines are tabulated in Table II. In Tables III and IV are shown the ascus analyses of the transferred chromosomes III from $S$. bayanus BK4505 and Danish lager strain BK2208. Agar plates with complete medium (YPD), sporulation media plates (SPOR) and defined minimal plates for genetic studies were made up according to Sherman, FinK, and Hicks (32). Plates used for selection of chromosome III transfers were prepared according to $(18,20)$.

\subsection{Preparation of DNA}

Total DNA from yeast cells was isolated according to PEDERSEN (26) and plasmid DNA was prepared and isolated in preparative scale according to Holmes and QUIGLEY (16). DNA preparations for OFAGE separations were made according to SCHWARTZ and CANTOR (31), with the modifications reported by PEDERSEN (27). 
Figure 2. Panel A: OFAGE separations of chromosomes from nine Saccharomyces species, which all contain RDN 1 form III (cf ref. $(24,27)$ and Table I). Lane a: S. uvarum CBS395, lane b: S. uvarum C81-1511, lane c: S. carlsbergensis NCYC396, lane d: S. carlsbergensis C84-AJL248 (mother strain for NCYC396 and CBS1513), lane e: S. carlsbergensis CBS1513, lane f: S. pastorianus NCYC392, lane g: S. pastorianus ATCC12752, lane h: S. bayanus NCYC374, and lane i: S. bayanus CBS380. The karyotypes of S. bayanus, S. pastorianus, and S. uvarum seem to be closely related, since the distribution of chromosome bands is almost identical. The three clones of the $S$. carlsbergensis bottom fermenting strain are identical, and the chromosomal band patterns are significantly different from the other three species. Arrowheads point to the chromosomes which hybridize with the HIS4 gene probe. Panel B: Corresponding Southern filter of the gel in panel A hybridized with the pC503 HIS4 probe used to monitor the chromosome IIIs in the different species. Even though the electrophoretic karyotypes of the three S. carlsbergensis clones are identical one difference between NCYC396 and the other clones C84-AJL248 and CBS1513 is seen. The uppermost of the three to HIS4 hybridizing bands in S. carlsbergensis C84-AJL248 and CBS1513 are missing in NCYC396.

The apparatus was constructed after the descriptions of CARLE and OLSON $(5,6)$.

\subsection{Molecular hybridization analysis}

Restriction endonucleases used in this study were obtained from Boehringer Mannheim and used according to MaNIATIS, FRITSCH, and SAMBROOK (19). Restricted DNA molecules were separated by gel electrophoresis in $0.7 \%$ agarose, $1 \times$ TBE buffer, while chromosome length DNA was separated by OFAGE in $1 \%$ agarose, $0.5 \times$ TBE buffer. The gels were stained with ethidium bromide in a concentration of 1 $\mu \mathrm{g} \cdot \mathrm{ml}^{-1}$ in the appropriate electrophoresis buffer. Conditions for OFAGE separations are as in (27). DNA fragments were transferred to nitrocellulose (Millipore HAWP 00010 or to Schleicher and Schuell BA85) by Southern transfer in $20 \times \operatorname{SSC}(33)$. The probes used in this study are pC503 $(H I S 4)(11,13)$ and the $0.9 \mathrm{~kb}$ EcoRI-SalI fragment (39) of pC512 (LEU2) (1, $2,7,10,15,34)$. Both genes originate from chromosome III in S. cerevisiae. Labelling of the probes was done by nick translation according to RIGBY et al. (29). Molecular hybridization of labelled probes to filterbound DNA was done in $3 \times$ SSC $+0.2 \%$ Denhardt solution (9) + preboiled salmon sperm DNA $\left(50 \mu \mathrm{g} \cdot \mathrm{ml}^{-1}\right)(17)$ at $60{ }^{\circ} \mathrm{C}$ for 18-24 hours (27). Exposure of autoradiographs was done at $-80^{\circ} \mathrm{C}$ with KODAK X-Omatic screens on KODAK XRP1 or XAR 5 films.

\section{RESULTS}

3.1. Electrophoretic karyotypes of S. bayanus, S. carlsbergensis, $S$. inusitatus, $S$. pastorianus, and $S$. uvarum

The electrophoretic karyotypes of the five species are shown in Figures 2 and 9. S. pastorianus and $S$. bayanus are considered according to VAN DER WALT (35) to be strains of the same species and restriction endonuclease fragment length polymorphisms at $R D N 1, H I S 4$, and LEU2 support this view $(24,27)$. The four strains included in the $\mathrm{S}$. bayanus group (Table I) are: S. pastorianus NCYC392, S. pastorianus ATCC12752, S. bayanus NCYC374, and S. bayanus CBS380. The karyotypes of the two $S$. pastorianus strains strains are identical (Figure 2 , lanes $f$ and $g$ ), in agreement with the statement in culture collection catalogues (Centraalbureau voor Schimmelcultures, Baarn 1983, List of Cultures 30th edition, 1983, CBS; American Type Culture Collection, Cataloque of strains I, 15th ed. 1982, ATCC; National Collection of Yeast Cultures, June 1981, NCYC) that both S. pastorianus strains are subclones of the authentic S. pastorianus (HANSEN). The major difference between $S$. bayanus (Figure 2, lanes $h$ and i) and S. pastorianus (Figure 2, lanes $f$ and $g$ ) is found in the number and intensity of the fastest moving chromosome bands. While there are three fast moving bands in S. bayanus there are only two in S. pastorianus. After hybridizing a blot of the gel in panel A to the pC503 HIS4 probe the autoradiogram of the filter (Figure 2B) identifies chromosomes III in identical positions 
M. B. PEDERSEN: DNA polymorphisms IV
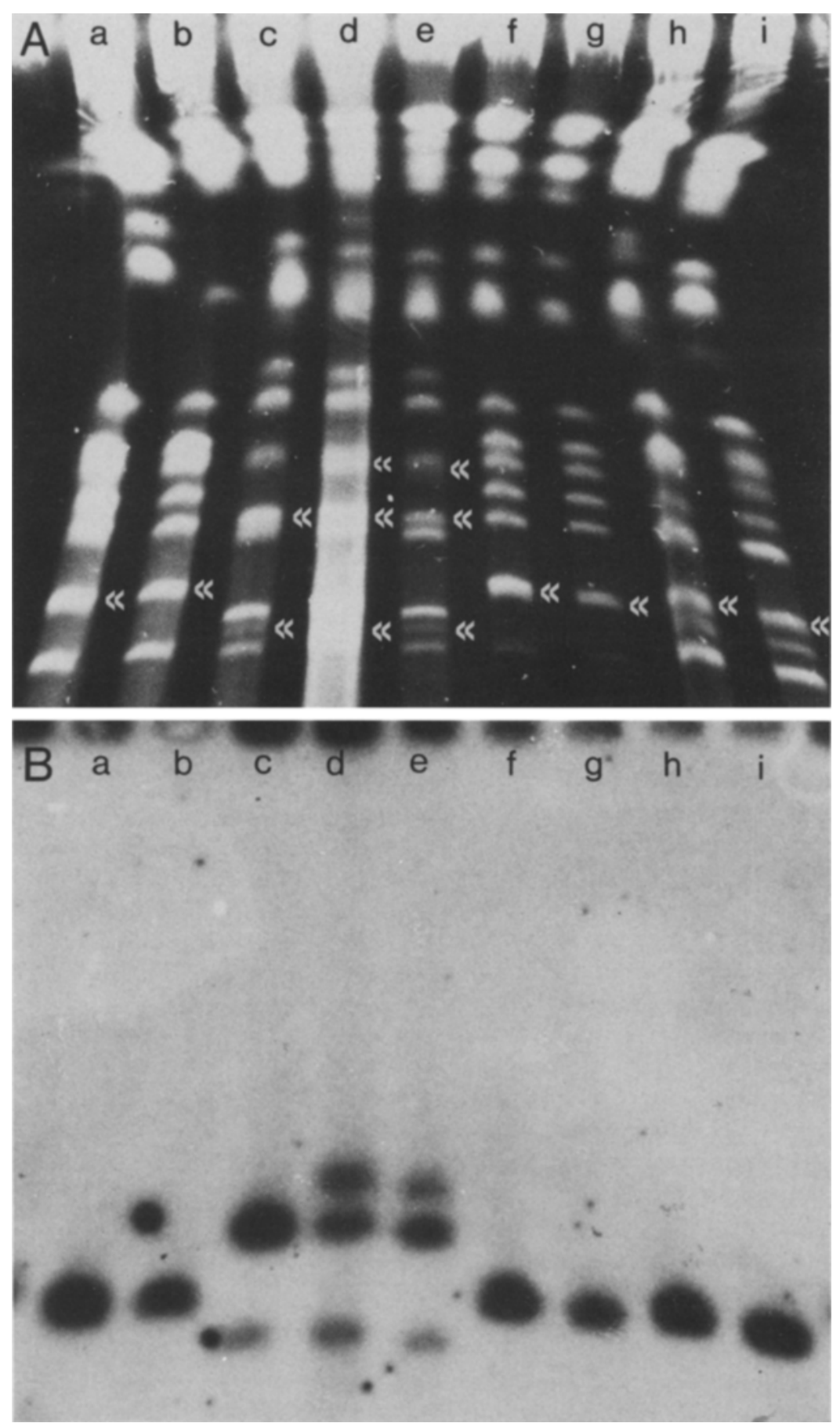
in the two species, i.e. in the second respectively third fastest moving chromosome band (arrowheads in lanes $\mathrm{f} \mathrm{to} i$ of Figure $2 \mathrm{~A}$ ). The karyotype of the two S. uvarum accessions CBS395 (C811510 and $C 81-1511)$ is identical with regards to the seven fastest moving bands (lanes $a, b$ in Figure 2A) and the autoradiogram of the filter probed with HIS4 identifies chromosome III in the same position as found for $\mathrm{S}$. bayanus and $\mathrm{S}$. pastorianus. The S. uvarum strain C81-1511 (Figure 2, lane b) lacks a chromosome band beween the very long and short chromosomes. S. inusitatus CBS1546 also has a single chromosome III band with a migration property comparable to $S$. uvarum (Figure 9, lane k versus lane b).

In contrast to the species just discussed the three $\mathrm{S}$. carlsbergensis strains have more than one chromosome band containing a HIS4 gene (Figure 2, lanes $\mathbf{c}, \mathbf{d}$, and e). The authentic $\mathbf{S}$. carlsbergensis bottom fermenting strains No. I in lane d (C84-AJL248, mother strain for NCYC396 and CBS1513) and lane e (CBS1513) has a karyotype with three chromosome bands hybridizing to the pC503 HIS4 probe. In this line there are apparently three homoeologous chromosomes III and its electrophoretic karyotype as a whole is very different from the karyotypes of the species in the $\mathrm{S}$. bayanus or $\mathrm{S}$. uvarum groups. Also derived from the authentic S. carlsbergensis bottom fermenting strain No. I is the culture NCYC396. This strain has only two chromosome bands, which hybridize with HIS4 (Figure 2, lane c). It lacks the longest band of the three which hybridize in the two other $S$. carlsbergensis accessions. Instead, there is a more intense hybridization and mass in the longer of the two chromosome bands containing a HIS4 gene. This may indicate the occurrence in this culture of a deletion in the longest of the three homoeologous chromosomes III.

In Figure 3 are compared the electrophoretic karyotypes of S. monacensis (CBS1503), which is the Carlsberg bottom fermenting yeast No. II (lane a), with those of the bottom fermenting yeast No. I (lane b), the Tuborg lager strain BK2224 (lane c), and the Carlsberg lager strain BK2246 (lane d). Interestingly, the Carlsberg and Tuborg lager strains have a single HIS4 probe hybridizing chromsome III band which

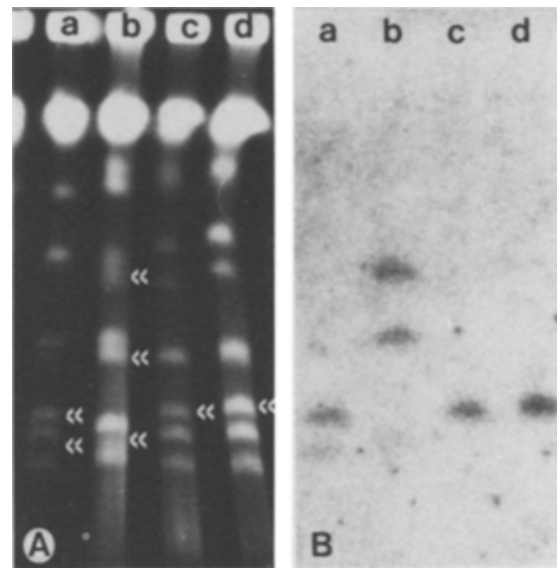

Figure 3. Comparison of chromosomes hybridizing to the HIS4 gene probe in the bottom fermenting strains: Lane a: S. monacensis CBS 1 503, lane b: S. carlsbergensis C84-AJL248, lane c: Tuborg lager strain BK2224, and lane d: Carlsberg lager strain BK2246. S. monacensis shows genomic relationship to both $\mathrm{S}$. carlsbergensis C84-AJL248 and the lager strains, since the S. monacensis strain contains two chromosome bands hybridizing to HIS4 of which the larger one has the same size as that hybridizing in the two lager strains and the shorter one is of a size corresponding to a HIS4 hybridizing chromosome in S. carlsbergensis C84AJL248. Panel A: Total electrophoretic karyotypes, panel B: Southern filter hybridized with pC503.

has the same mobility as the longer of the two chromosome III bands in S. monacensis. The second shorter and more weakly hybridizing band in $\mathrm{S}$. monacensis has a mobility comparable to a chromosome III band present in the S. carlsbergensis bottom fermenting yeast No. I.

In Figure 4 are shown electrophoretic karyotypes of S. carlsbergensis No. I (248), S. monacensis (1503), the Pschorr lager strain (1101), the Tuborg lager strain (2224), and the Carlsberg lager strain (2246). The roman numerals on the left correspond to the positions of the chromosomes in the genetic standard strain K5-5A. The Tuborg, the Carlsberg, and the Pschorr strain have identical chromosome band patterns except for the band identified with double-headed arrow, which in the Pschorr strain moves slower than in the other two strains. The S. monacensis 


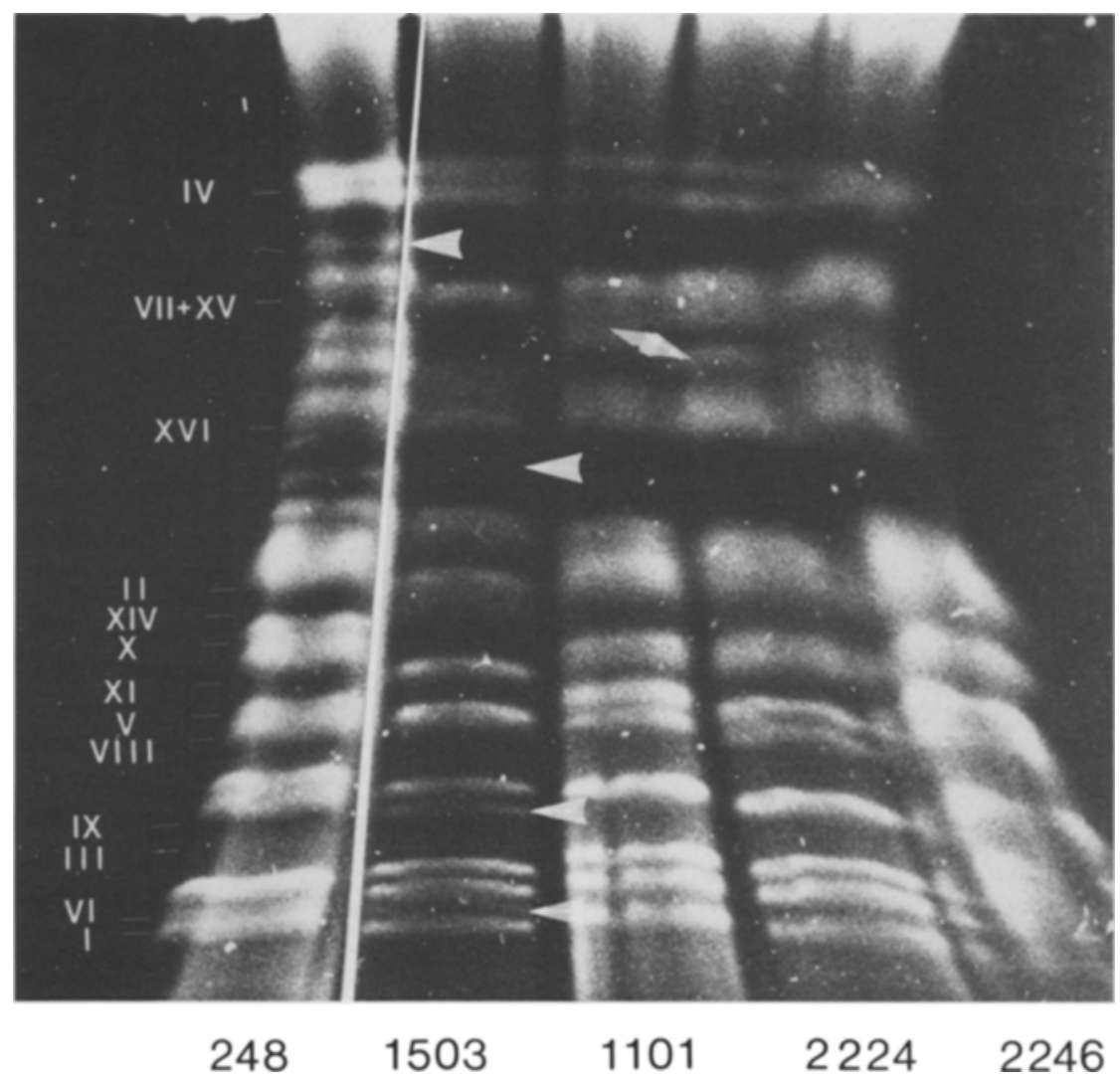

Figure 4. Electrophoretic karyotypes of five bottom fermenting strains: Lane 248: S. carlsbergensis C84-AJL248, lane 1503: S. monacensis CBS1 503, lane 1101: Pschorr lager strain BK1 101, lane 2224: Tuborg lager strain BK2224 and lane 2246: Carlsberg lager strain BK2246. The white arrows point at chromosomal bands in 248 and 1503 which are absent in the lager strains. The double headed arrow at lanes 1101 and 2224 points to a chromosomal band which in BK1101 and BK2224 differs in mobility. The roman numbers refer to band positions of the chromosomes in S. cerevisiae K5-5A.

and S. carlsbergensis No. I karyotypes differ by a number of bands (marked with arrows in Figure 4). Both of these strains have karyotypes distinguishable from the three subsequently employed lager strains.

\subsection{Segregation of chromosomes III from $\mathrm{S}$. bayanus NCYC374}

S. bayanus NCYC 374 could be sporulated on YPD medium as well as on sporulation medium at $20{ }^{\circ} \mathrm{C}$. Tetrads were dissected and individual spores grown. No more than two spores per ascus germinated. Homothallic spore clones were analysed for their chromosme III constitution in Southern blots with the HIS4 probe (Figure 5). S. bayanus (lane 374) is characterized by six Sall HIS4 fragments, two of which are known as pattern II $(6.7 \mathrm{~kb}$ and $2.3 \mathrm{~kb})$, while the other four fragments $(6.4 \mathrm{~kb}, 5.5 \mathrm{~kb}, 2.1 \mathrm{~kb}$, and $1.6 \mathrm{~kb}$ ) originate from a chromosome designated pattern III. The five spore clones analyzed in Figure 5 reveal the segregation of these two types of chromosomes: Clones $-4 \mathrm{~A},-4 \mathrm{~B}$, and $-5 \mathrm{~A}$ contain only chromosomes with pattern III and clone $-7 \mathrm{~B}$ contains exclusively pattern II. The 


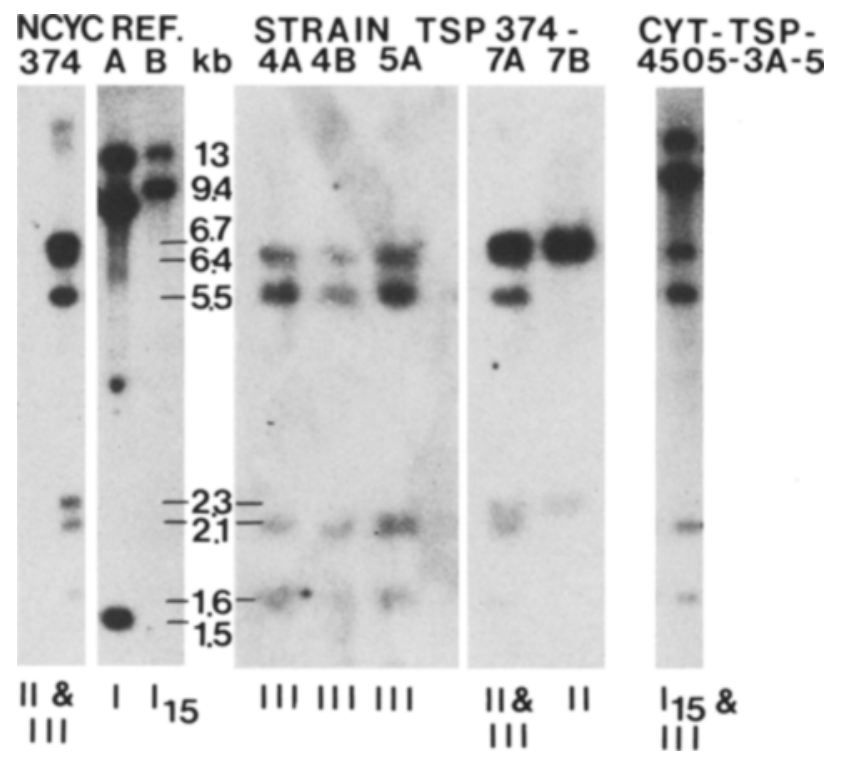

Figure 5. HIS4 Sall restriction endonuclease fragment patterns of S. bayanus NCYC374, of S. cerevisiae $\mathrm{S} 288 \mathrm{C}=$ Reference A, of S. cerevisiae K5-5A his 4-15 = Reference B and of clones from ascospores TSP-374-4A, -4B, -5A, $-7 \mathrm{~A}$ and $-7 \mathrm{~B}$. NCYC 374 contains HIS4 patterns II and III, while spore clones $-4 \mathrm{~A},-4 \mathrm{~B}$ and $-5 \mathrm{~A}$ contain HIS4 pattern III and -7B contains pattern II. Spore clone TSP-374-7A carries both HIS4 patterns II and III. 4505-3A-5 is a chromosome addition line containing patterns I his $4-15$ and III together. Fragment sizes are in thousand of basepairs $(\mathrm{kb})$.

clone -7A has both types of chromosomes i.e. pattern II and III. To confirm that the spore clones are actual meiotic products from $\mathrm{S}$. bayanus electrophoretic karyotypes were established for the $S$. bayanus parental strain and its progeny (Figure 6A). Segregation of several chromosomes are seen in the spore clones (Figure 6A, white arrow heads). The HIS4 probe pC503 has been hybridized to the corresponding Southern filter of the gel (Figure 6B). NCYC374 contains a chromosome III doublet (Figure 6A, double white arrow heads) which has segregated in its progeny. Thus the spore clones $-4 \mathrm{~A},-4 \mathrm{~B}$, and $-5 \mathrm{~A}$ with the HIS4 pattern III have only the upper chromosome of the doublet, while the spore clone $-7 \mathrm{~B}$ containing only pattern II carries the lower chromosome of the doublet. It is also obvious that the spore clone $-7 \mathrm{~A}$ with both patterns II+III contains the doublet. That the latter is a meiotic segregant is shown by the absence of at least one chromosome (corre- sponding in size to chromosome VI of the reference strain).

\subsection{Genetic mapping of a S. bayanus chromo- some III}

S. bayanus strain BK4505 is a subculture of NCYC374 and has been kept for several years at the Department of Brewing Chemistry. It sporulates on YPD medium like NCYC374. It was sporulated and yielded one ascus with four spores. The four spore clones of this ascus were homothallic and contained only the HIS4 pattern III. One of the clones was sporulated and mixed with a large surplus of cells from the chromosome III receptor strain K5-5A ( $\alpha$, his415, ade2-1, canl, karl-I) and the mixture was plated on a YPD plate and incubated at $27^{\circ} \mathrm{C}$ for 18 hours. After the incubation the cells were washed off and plated on a defined complete medium plate minus histidine plus canavanine 

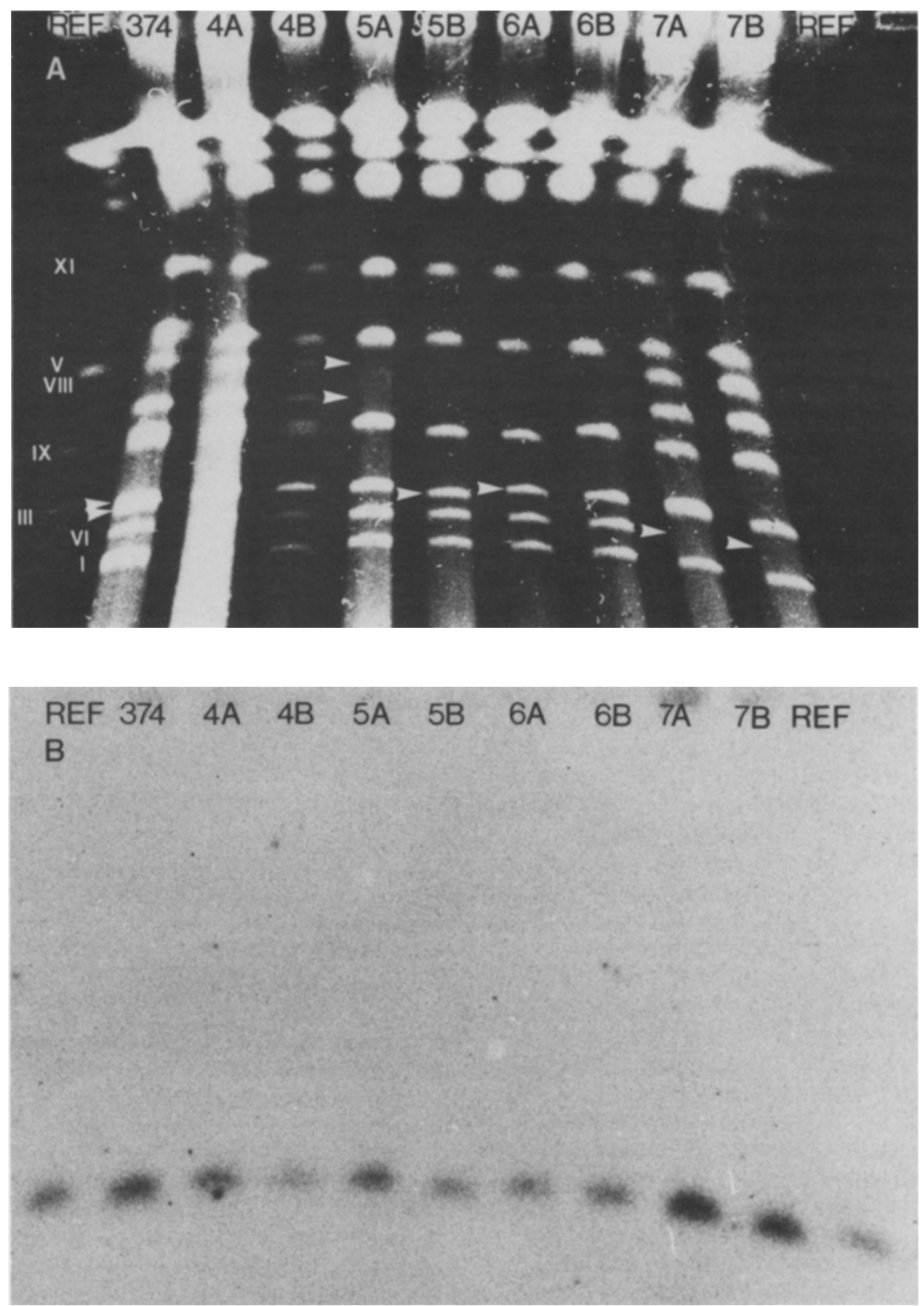

Figure 6. Electrophoretic karyotypes of ten Saccharomyces strains. Panel A: Ref. lane: S. cerevisiae genetic standard strain C81-1611, lane 374: S. bayanus 374, lanes 4A to 7B: Surviving tetraspores from dissected asci of $S$. bayanus NCYC374. Roman numerals correspond to chromosomes in S. cerevisiae C81-1611. White arrow heads point at chromosomal bands in NCYC374 which have segregated in the ascospore clones. Panel B: Corresponding Southern filter hybridized with HIS4 probe pC503, thus revealing the position of chromosome III in S. bayanus NCYC374. 
Table III. Ascus analysis of cross between S. bayanus chromosome III addition line CYT-TSP-4505-3A-5 and S. cerevisiae chromosome tester strain C79-992:

\begin{tabular}{|c|c|c|c|c|c|c|c|}
\hline & $4: 0$ & $2: 1$ & $2: 2$ & $1: 2$ & $1: 3$ & $0: 3$ & $0: 4$ \\
\hline HIS4/his4 & & 6 & 10 & 2 & 1 & & \\
\hline LEU2/leu2 & & 6 & 10 & 2 & 1 & & \\
\hline THR4/thr4 & & 7 & 11 & 1 & & & \\
\hline ADE2/ade2 & & 3 & 10 & 5 & 1 & & \\
\hline \multirow[t]{4}{*}{ URA4/ura4 } & & 1 & 2 & 5 & 5 & 2 & 4 \\
\hline & & PD & NPD & TT & & & \\
\hline & HIS4-LEU2 & 19 & & & & & \\
\hline & LEU2-THR4 & 6 & & 13 & & & \\
\hline
\end{tabular}

and adenine. Red actively growing colonies were selected after a week. Their growth was dependent on the transfer of an S. bayanus chromosome III with a functional complementing HIS4 gene. The colony designated CYT-TSP-45053A-5 (Figure 5) reveals in the Southern blot the HIS4 pattern I-15 characteristic for the his4-15 allele with its 500 base pair deletion (14) including a Sall site and pattern III from the S. bayanus chromosome transferred. In Figure 5 is also given the comparison of a wild type HIS4 pattern I and the pattern I-15 of the his4-15 recipient strain. Due to the elimination of a Sall site the latter has a restriction fragment of 10.4 $\mathrm{kb}$ instead of the two fragments with the size of 9.3 and 1.5 derived from the HIS 4 wild type gene.

The disomic chromosome III addition line was crossed by rare mating with C79-992 ( $\alpha$, his4-644, leu2, thr4, ura4) and plated on minimal medium which will select for a strain containing the $\alpha$, his 4-644 carrying chromosome together with chromosome III from S. bayanus. A prototrophic colony was picked, grown, and sporulated. The ascus analysis is presented in Table III. In 19 asci analysed no recombinants were found in the interval HIS4$L E U 2$, while 13 tetratypes and 6 parental ditypes were counted when the LEU2-THR 4 region was analysed. This corresponds to $34 \mathrm{cM}$, which indicates that the recombination frequency in this interval is similar to that observed in the $\mathrm{S}$. cerevisiae chromosome III and the S. carlsbergensis chromosome III with the HIS4 pattern II. The latter chromosome is also charac- terised by the absence of crossing over in the HIS4-LEU2 interval. Chromosome transfer from tetraspores TSP-374-4B (HIS4 pattern III) and TSP-374-7B (HIS4 pattern II) has been attempted, but only one very unstable reddish colored histidine prototroph cytoductant was found in the cross between TSP-374-4B and K5-5A.

\subsection{Chromosome III transfer from the Danish lager strain BK2208 \\ Lager strain BK2208 has formerly been used} as a production strain at the Tuborg brewery. As seen from Table I the molecular markers $R D N I$, $H I S 4$, and LEU2 of this strain are those characteristic for the bottom fermenting yeasts. The strain has the $T y$ pattern Ila. A culture of this strain was sporulated and harvested spores were mixed with a surplus of cells from the chromosome III receptor strain $\mathrm{K} 5-5 \mathrm{~A}$. A chromosome addition line was obtained in the same way as described above in the $\mathbf{S}$. bayanus cross and a substitution line identified by the expression of the $a$ mating type. The DNA of these two strains was digested with Sall and the separated restriction fragments probed for the HIS4 and LEU2 patterns (Figure 7). The chromosome substitution line CYT-MSP-2208-2 contains only HIS4 pattern II (from strain BK2208) while the addition line CYT-MSP-2208-7 contains both patterns II and I-15 from the receptor strain. In agreement with these results the substitution line CYT-MSP-2208-2 carries $L E U 2$ fragment IV, while the addition line also has fragment I from 

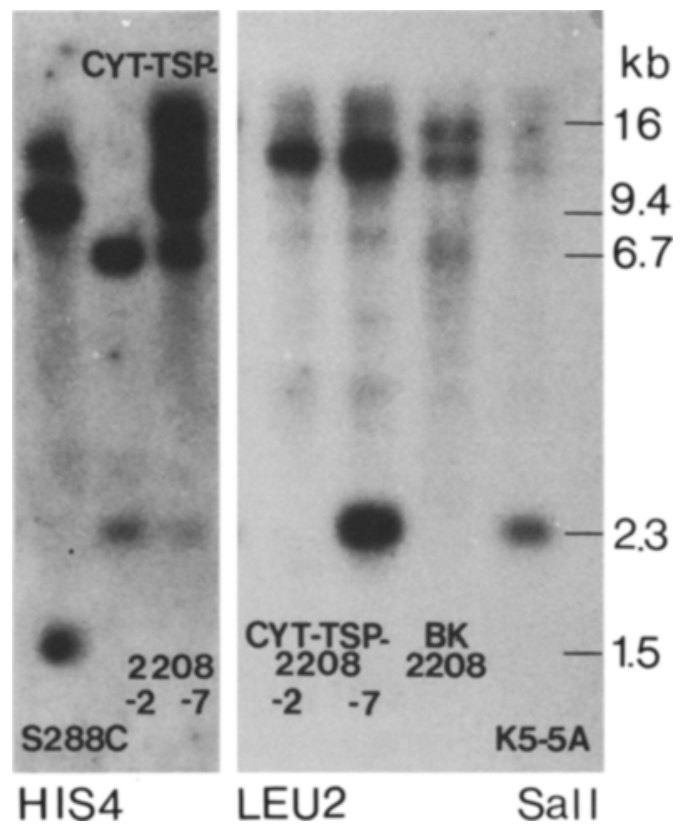

Figure 7. Restriction endonuclease fragment patterns of HIS4 and LEU2 of chromosome substitution line CYT-MSP-2208-2 and chromosome addition line CYT-MSP-2208-7 together with S. cerevisiae reference strains $\mathrm{S} 288 \mathrm{C}$ and $\mathrm{K} 5-5 \mathrm{~A}$. The restriction pattern analyses show that $L E U 2$ fragment IV is linked to HIS4 pattern II in BK2208. the receptor strain. This shows that fragments III, IV and I segregate independently.

The ascus analysis of the cross of the substitution line with the $S$. cerevisiae tester strain C79-992 (Table IV) gave the following results: Only four of the 27 tetrads contained four viable spores, the rest had three viable spores. Since the classes 2:1 and 1:2 are of the same size, 2:2 segregation of the chromosomes has been assumed. No recombination has occurred between HIS 4 and $L E U 2$ or between $L E U 2$ and MAT. For the recombination between $M A T$ and $T H R 4$ a genetic distance of $22 \mathrm{cM}$ is calculated on the basis of 26 asci.

The result with the chromosome III transfer from strain BK2208 are in agreement with the result in (21) for the Carlsberg lager strain BK2246. Electrophoretic karyotypes reveal the following about the size of the genetically mapped chromosome III in the BK2208 lager strain. Chromosome III in the receptor strain $\mathrm{K} 5-5 \mathrm{~A}$ is marked in Figure 8 and also present in the CYT-MSP-2208-7 addition line. This chromosome is absent in the substitution line and the donor strain, both of which have a shorter chromosome III. The autoradiogram in Figure $9 \mathrm{~B}$ of the Southern blot identifies the two chromosomes in the addition line (lane g), while $\mathrm{K} 5-5 \mathrm{~A}$ in lane e has the long chromosome III and the donor BK2208 in lane $h$ the short chromosome III, which is also present in lane $\mathrm{f}$ containing the chromosomes of the substitution line.

Table IV. Ascus analysis of cross between S. carlsbergensis chromosome III substitution line CYT-MSP-2208-2 and S. cerevisiae tester strain C79-992:

\begin{tabular}{|c|c|c|c|c|c|c|c|c|c|}
\hline & $4: 0$ & $3: 1$ & $3: 0$ & $2: 1$ & $2: 2$ & $1: 2$ & $0: 3$ & $1: 3$ & $0: 4$ \\
\hline HIS4/his4 & & & & 11 & 4 & 12 & & & \\
\hline LEU2/leu2 & & & & 11 & 4 & 12 & & & \\
\hline$M A T a / M A T \alpha$ & & & & 11 & 4 & 12 & & & \\
\hline$T H R 4 / t h r 4$ & 1 & 1 & & 13 & 2 & 10 & & & \\
\hline$A D E 2 / a d e 2$ & & & & 12 & 4 & 11 & & & \\
\hline \multirow[t]{5}{*}{ URA4/ura4 } & & & & 15 & 4 & 8 & & & \\
\hline & & & PD & NPD & TT & & & & \\
\hline & $H I S$ & & 27 & & & & & & \\
\hline & $L E$ & & 27 & & & & & & \\
\hline & $M A$ & $R 4$ & 14 & & 12 & & & & \\
\hline
\end{tabular}




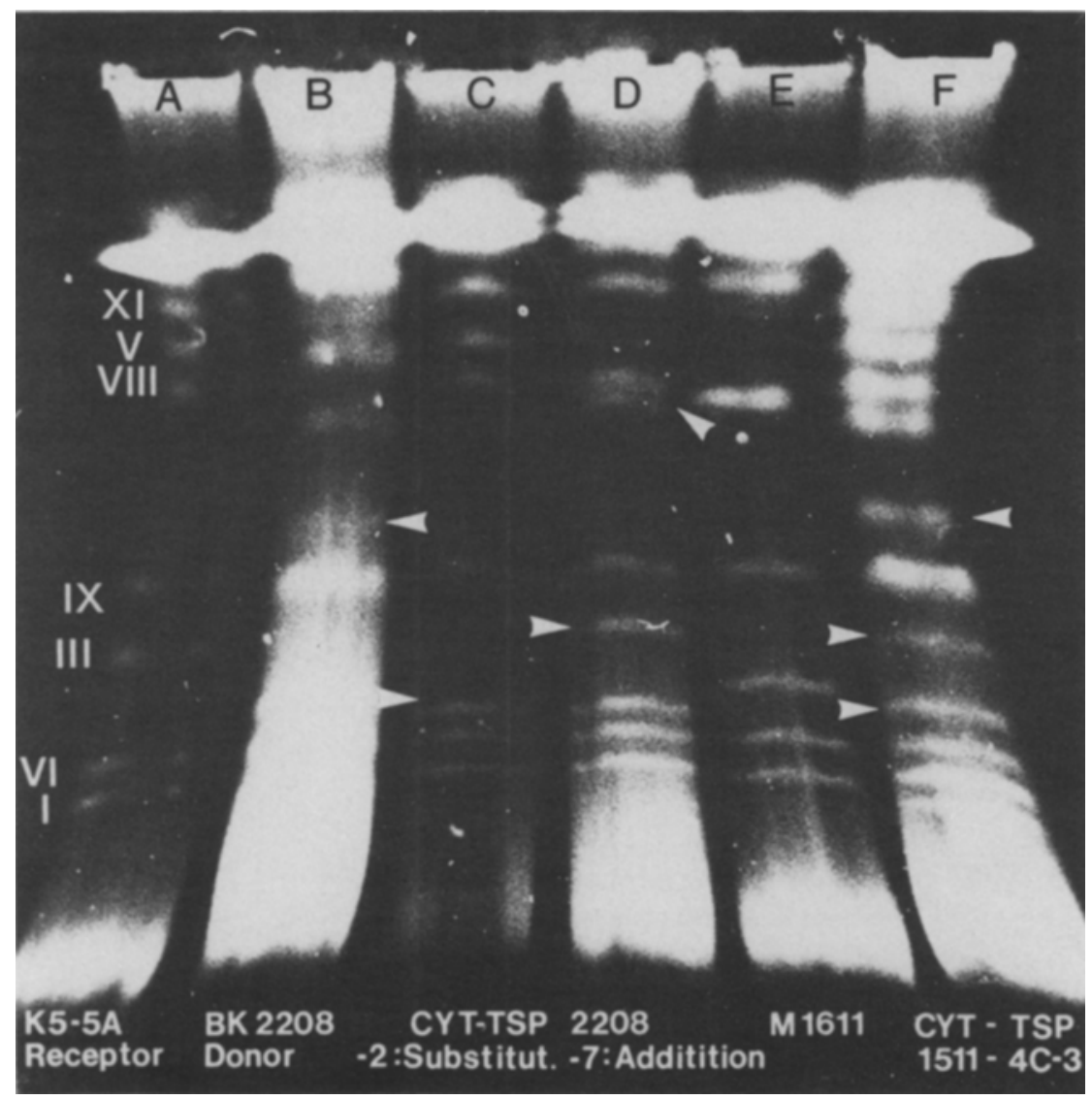

Figure 8. OFAGE chromosomal separations of chromosomal addition and substitution lines together with parental strains. From left to right: S. cerevisiae K5-5A receptor strain for chromosome III, Danish lager strain BK2208, chromosome III substitution line CYT-MSP-2208-2, chromosome III addition line CYT-MSP-2208-7, S. cerevisiae chromosome size reference strain C81-1611, addition line CYT-TSP-1511-4C-3 for chromosome III from S. uvarum C81-1511. Preferential separation of short chromosomes, $1.5 \%$ agarose and 35 seconds pulsetime.

\subsection{Transfer of chromosome III from S. uvarum C81-1511 to $S$. cerevisiae}

Chromosome III from S. uvarum has been transferred to $S$. cerevisiae in cytoductants with the aid of the karl gene. The mother strain was sporulated and asci with four surviving spores obtained. The receptor strain K5-5A was mated with the homothallic spore isolates TSP-1511$4 A,-4 B,-4 C$, and $-4 D$. Only one chromosome addition line in the form of a red histidine prototroph was obtained, namely CYT-TSP1511-4C-3 (Figure 8). The karyotype reveals it to be disomic for chromosome llI. Figure 9 demonstrates in lane $b$ that chromosome III of $\mathrm{S}$. uvarum is shorter than chromosome III of the receptor strain K5-5A (lane e). The addition line karyotype in Figure 8 contains both these chromosomes and in addition at least two other chromosomes, one with a faster migration than chromosome III in the receptor strain and another one with a size intermediate between chromosome IX and VIII.

Since CYT-TSP-1511-4C-3 is disomic for chromosome III low mating efficiency is seen. The line was mated with both C79-992 ( $\alpha)$ and C79-993 (a). In Figure 10 is shown a Southern blot of the Sall digested DNA from all hybrids obtained on minimal media plates (lanes a to h, 

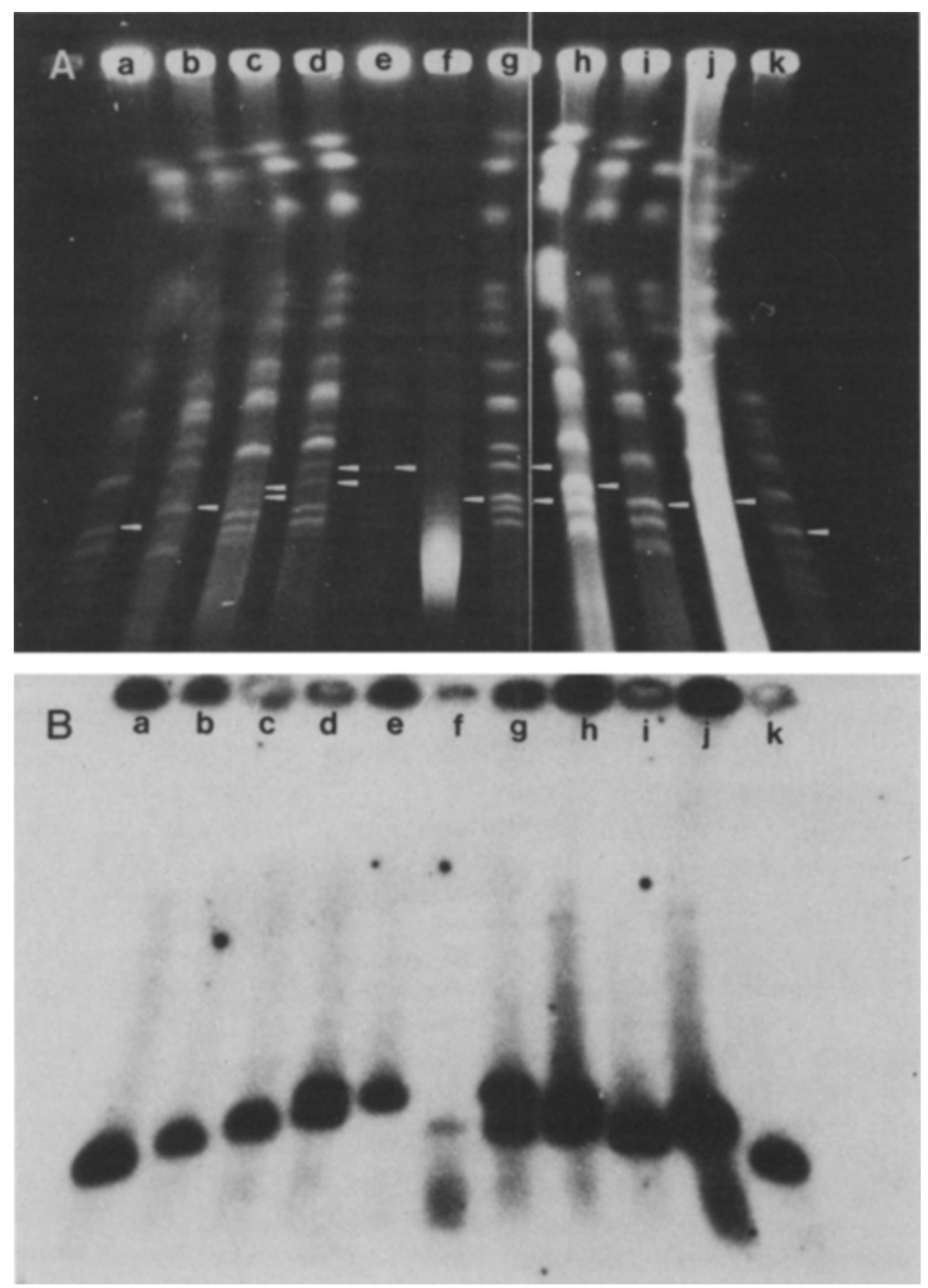

Figure 9. OFAGE chromosome separations of parental strains and chromosome III addition and substitution lines. Lane a: S. carlsbergensis Tuborg lager strain BK2224, lane b: S. uvarum C81-1511, lane c: hybrid strain CYT-TSP-151 1-4C-3 × C79-992-3A, lane d: hybrid strain CYT-TSP-1511-4C-3 $\times$ C79-992-3B, lane e: S. cerevisiae chromosome III receptor strain K5-5A, lane f: substitution line CYT-MSP-2208-2 (partially degraded), lane g: addition line CYT-MSP-2208-7, lane h: S. carlsbergensis BK2208, lane i: Carlsberg lager strain BK2246, lane j: S. cerevisiae genetic standard strain strain S288C, and lane k: S. inusitatus CBS1546. Panel A: Total electrophoretic karyotypes and panel B: Corresponding Southern filter hybridized with HIS4 probe pC503.

CYT-TSP-1511-4C-3 $\times \alpha$ C79-992 and lanes $i$ to r, CYT-TSP-1511-4C-3 $\times$ a C79-993. The blot was probed with the nick translated HIS4 gene and the patterns of the two parents are given at right. The trisomic sum of the two patterns and the wild type HIS4 pattern from C79-992 or C79-993 is seen in e.g. lane $d$ and lanes $i$ to $r$. When mated to C79-992 the his4-15 allele is absent in some progenies (lanes $a, b$, and c) leaving the $\mathrm{S}$. uvarum chromosome III together 


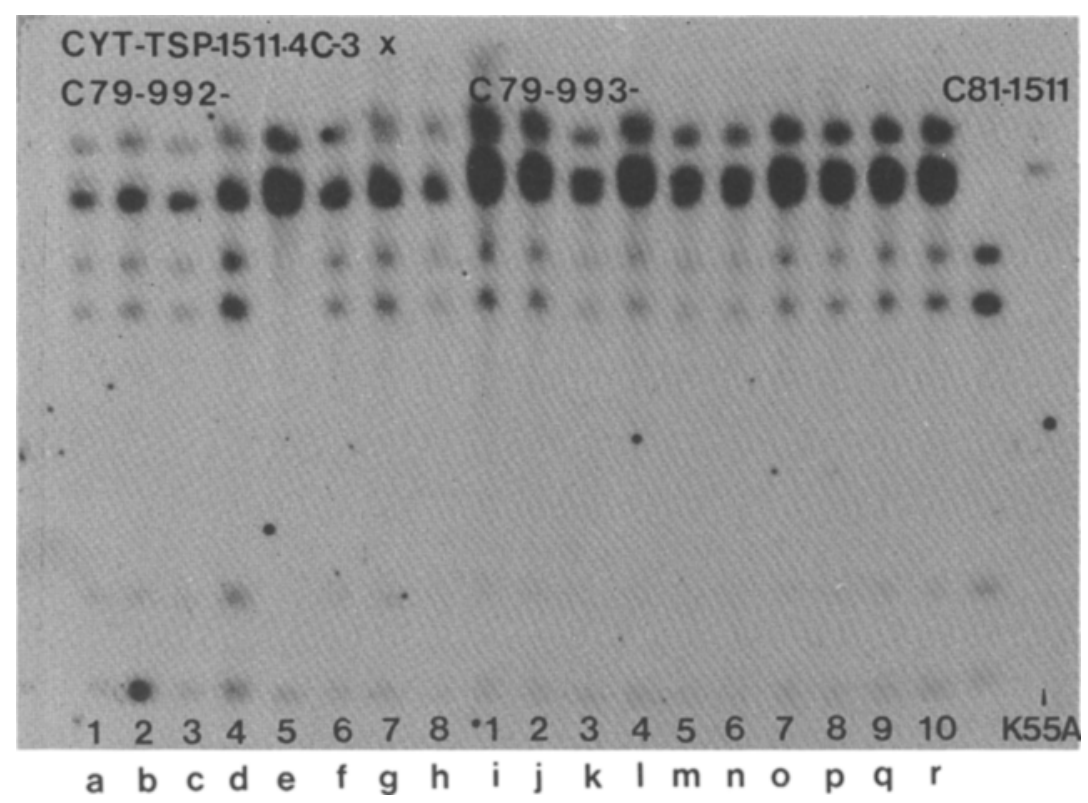

Figure 10. Sall restriction endonuclease treated DNAs hybridized with HIS4 probe pC503. Lanes a to h: offspring from the cross between CYT-TSP-151 1-4C-3 $\times$ C79-992. Seven of the strains contain HIS4 patterns I and III with traces of pattern I-15. One strain (-5) has lost pattern III. Lanes i to r: The progeny from the cross CYT-TSP-1511-4C$3 \times$ C79-993 all seem to contain HIS4 patterns I, I-15 and III and are thus trisomic for chromosome III.

with the S. cerevisiae chromosome III. In lane e a hybrid is depicted, which has lost the $\mathrm{S}$. uvarum chromosome. The eight hybrid offsprings from the mating between the cytoductant and C79-992 were obviously unstable, since they show a variety of colony colours and shapes. The hybrid strain CYT-TSP-1511-4C-3 x C79. 992-3 was chosen for further analyses since it seemed to contain only the S. uvarum chromosome III together with the chromosome III from C79-992. It was reisolated several times and divided into two lines, a "brown" $-3 \mathrm{~A}$ and a "white" -3B line. In Figure 9, lanes $c$ and $d$ are shown the OFAGE separations of the two lines and as indicated by the arrow heads each one has retained only two chromosomes III. Line -3B has lost chromsome III from S. uvarum and has retained chromosome III from K5-5A, while the $-3 \mathrm{~A}$ line shows the reverse situation, it has kept the S. uvarum chromosome III and has lost the K 5-5A chromosome. The other chromosomal bands seem to be unaltered. The CYT-TSP1511-4C-3 $\times$ C79-992-3A hybrid was picked and analysed. Very few, three and four spored asci formed upon sporulation, so a genetic map could not be derived for the transferred $S$. uvarum chromosome III.

In Figure 11 are shown the Saccharomyces lines which have been used for characterization of the S. uvarum C81-1511 chromosome III. The Southern blot of the restricted DNAs have been hybridized to the nick translated HIS4 probe. Each strain has been digested separately by EcoRI, SalI, and HindIII. In lanes $a$ and $b$ are shown the $-3 A$ and $-3 B$ hybrid lines with and without the $\mathrm{S}$. uvarum chromosome III, in lanes $\mathrm{c}$ and $\mathrm{d}$ are shown C81-1511 (S. uvarum) and TSP-1511-4C (S. uvarum spore clone), while in lanes $\mathrm{e}, \mathrm{f}$, and $\mathrm{g}$ are presented DNAs from CYT-TSP-1511-4C-3 (S. uvarum chromosome III addition line), K5-5A and C79-992. In lane a is seen HIS4 pattern I and III together, in b HIS4 pattern I-15 and I. HIS4 pattern III alone is seen in S. uvarum DNA in lane $c$ and in its spore clone in d, while pattern I-15 and III are together in the DNA of the addition line in lane e. The two S. cerevisiae strains in lanes $f$ and $g$ contain pattern I-15 and I respectively. 


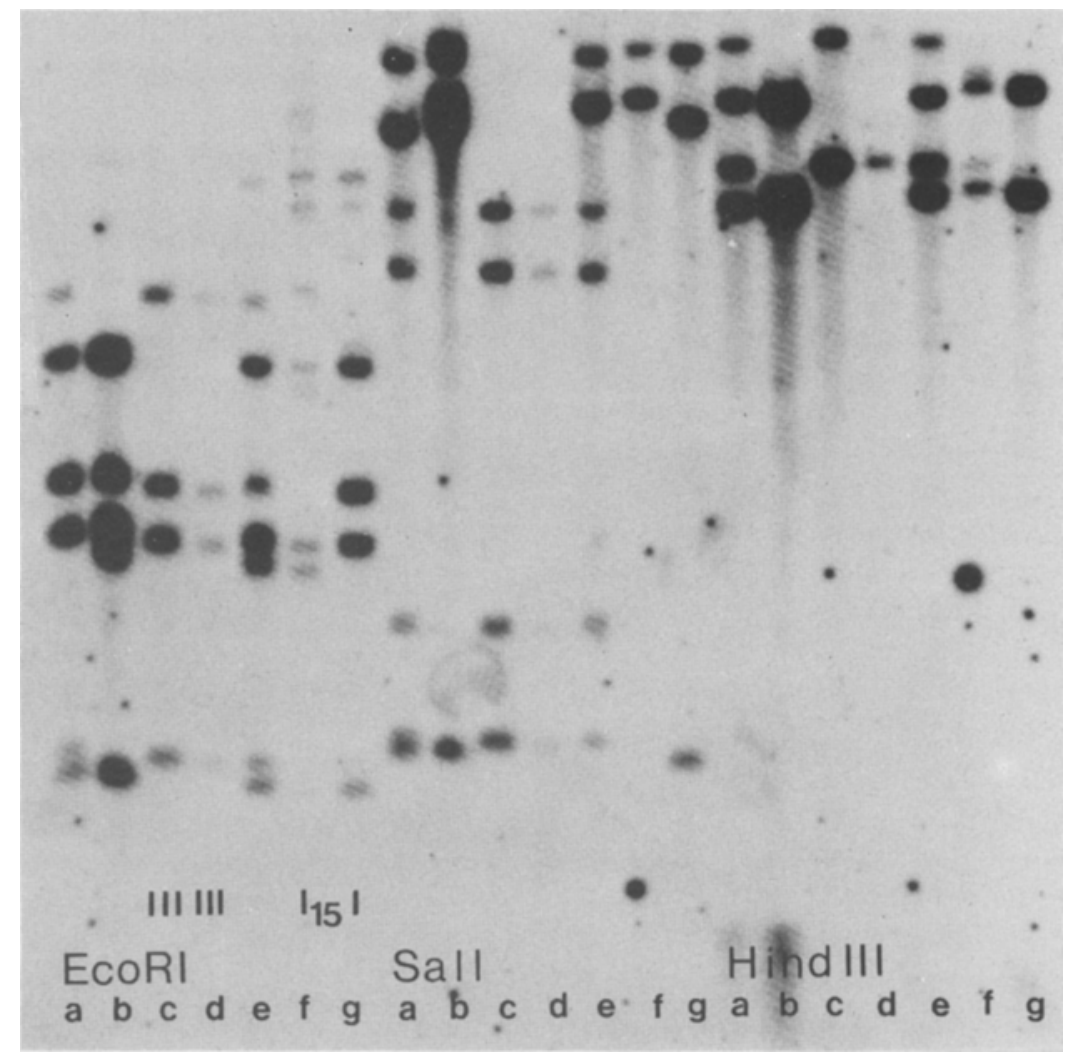

Figure 11. Restriction endonuclease fragment patterns of DNA from seven Saccharomyces strains, digested with EcoRI, Sall or HindIII, respectively, and probed with HIS4 pC503. Strain a: hybrid strain CYT-TSP-1511-4C-3 $\times$ C79-992-3A ("brown" line), strain b: hybrid strain CYT-TSP-1511-4C-3 × C79-992-3B ("white" line), strain c: S. uvarum C81-1511, strain d: S. uvarum tetraspore TSP-1511-4C, strain e: chromosome addition line CYT-TSP-151 I-4C-3, strain f: S. cerevisiae chromosome III receptor strain K5-5A, and strain g: S. cerevisiae tester strain C79-992. The hybrid strain in lane a contains both HIS4 from S. cerevisiae C79-992 and from S. uvarum C81-1511, while the hybrid in lane b contains the two S. cerevisiae HIS4 alleles, HIS4 pattern I-15 from K5-5A, and HIS4 pattern I from C79-992. Lanes c and d contain HIS4 pattern III, while lane e contains S. uvarum HIS4 pattern III together with S. cerevisiae HIS4 pattern I-15.

\section{DISCUSSION}

In Figurè 1 a partial genetic map is drawn for the chromosome III of S. bayanus which could be transferred into a marked cerevisiae line and analysed. It reveals two important features: The $\mathrm{S}$. bayanus genes which can functionally complement the HIS4, LEU2, and THR4 genes of cerevisiae are found on the same chromosome. As is the case for chromosomes III from the Carlsberg lager strain BK2246 (21) and the Danish lager strain BK2208, cross over occurs between the bayanus and cerevisiae chromosomes III in the LEU2 THR4 interval but not in the HIS4-LEU2 interval. Although the genetic map of chromosome III of S. carlsbergensis and S. bayanus are similar, distinct differences between the karyotypes of these two species have been observed. The similarity of the karyotypes of $\mathrm{S}$. bayanus, $\mathrm{S}$. inusitatus, and $\mathrm{S}$. uvarum is attested by the restriction endonuclease fragment patterns of RDN1, HIS4, LEU2, and DNA-DNA reassociation kinetics $(4,23,24,25$, 27, 30). Since S. bayanus NCYC374 shows composite restriction endonuclease fragment patterns at the HIS4 locus $(24,25,27)$, and independent segregation of these patterns in 
spore clones more than one chromosome III are present in the genome of S. bayanus. A heterologous origin of these chromosomes III is therefore indicated like in the Carlsberg lager strain BK2246 $(21,22,36,37)$. The reason for obtaining only a few chromosome addition lines, when $\mathrm{S}$. bayanus or $\mathrm{S}$. uvarum is used as donor chromosome to $S$. cerevisiae lines is unknown. WINGE and LAUSTSEN (38) found only 3 germinating spores out of 182 ( $2 \%$ germination) from a sporulated hybrid between $S$. cerevisiae and $S$. validus, while hybrids between Danish bakers yeast and other $\mathrm{S}$. cerevisiae strains had a germination frequency of $59 \%$ to $94 \%$ (38). In S. bayanus extensive chromosome length polymorphisms are uncovered when the chromosomes are segregated into spores (cf Figure 6). Further analyses will show to what extent the chromosomal bands in NCYC374 are homoeologous.

There seem to be three major types of bottom fermenting strains, namely: S. carlsbergensis C84-AJL248, modern lager strains and S. monacensis. Whereas modern lager strains have homoeologous chromosomes III which in electrophoretic separations display uniform length, the type strains of S. carlsbergensis C84-AJL248 and S. monacensis CBS 1503 contain homoeologous chromosomes III of 3 or 2 significantly different sizes (Figures 3 and 4). The chromosome III length of the modern lager strains is comparable to that of one of the chromosomes III of S. monacensis, but not found in carlsbergensis C84-AJL248. At the level of small segments of the homoeologous chromosomes, the $H I S 4, L E U 2$, and $T y l$ restriction endonuclease fragment patterns of $S$. carlsbergensis C84AJL248 resemble the lager strains closely (27). In short, S. monacensis traits are found both in the modern lager strains and $S$. carlsbergensis C84-AJL248. Since the lager strains and S. carlsbergensis C84-AJL248 contain S. cerevisiae related alleles of at least $H I S 4$ and $L E U 2$, it is suggested that $\mathrm{S}$. monacensis is one of the parental strains for the two, and that the other parental strain is a $\mathbf{S}$. cerevisiae top fermenting yeast. When E. CHR. HANSEN described the two species S. carlsbergensis and S. monacensis (12), he had established that the yeast used in 1882 1883 at the Carlsberg brewery was a mixture of several lines of which $\mathrm{S}$. carlsbergensis No. I was one of them and $\mathrm{S}$. monacensis another one (line No. II). He suggested that the latter line originated from breweries in Munich (12). Further studies of single chromosome transfers with OFAGE separations of chromosomes accompanied by molecular hybridizations and tetrad analysis will elucidate the genotypic organization and evolution of Saccharomyces bayanus, S. carlsbergensis, S. monacensis, and S. uvarum.

\section{ACKNOWLEDGEMENTS}

I would like to thank DITER VON WETTSTEIN, Morten C. Kielland-Brandt, Torsten NilsSON-Tillgren, and POUl SigsgaARD for encouragement, interest, and stimulating discussions during this study, SUSANNE BRUUN for excellent technical assistance and NINA RASMUSSEN for figure preparations.

\section{REFERENCES}

1. Andreadis, A., Y. -P. Hsu, G. B. Kohlhaw \& P. SCHIMMEL: Nucleotide sequence of yeast LEU2 shows 5 -noncoding region has sequences cognate to leucine. Cell 31, 319-325 (1982)

2. Baichwal, V. R., T. S. CunNingham, P. R. GatZEK \& G. B. KOHLHAw: Leucine biosynthesis in yeast. Curr. Genet. 7, 369-377 (1983)

3. Barnett, J. A., R. W. Payne \& D. Yarrow: Yeasts: Characteristics and identification. Cambridge University Press (1983)

4. Bicknell, J. N. \& H. C. Douglas: Nucleic acid homologies among species of Saccharomyces. $\mathrm{J}$. Bacteriol. 101, 505-512 (1970)

5. Carle, G. F. \& M. V. Olson: Separation of chromosomal DNA molecules from yeast by othogonal-field alternation gel electrophoresis. Nucl. Acid Res. 12, 5647-5664 (1984)

6. Carle, G. F \& M. V. Olson: An electrophoretic karyotype for yeast. Proc. Natl. Acad. Sci. USA 82, 3756-3760 (1985)

7. Chinault, A. C. \& J. Carbon: Overlap hybridization screening: lsolation and characterization of overlapping DNA fragments surrounding the LEU2 gene on yeast chromosome III. Gene 5, $111-126(1979)$

8. CONDE, J. \& G. R. FinK: A mutant of Saccharomyces cerevisiae defective for nuclear fusion. Proc. Nat. Acad. Sci. USA 73, 3651-3655 (1976)

9. DENHARDT, D. T: A membrane - filter technique 
for the detection of complementary DNA. Biochem. Biophys. Res. Commun. 23, 641-646 (1966)

10. Dobson, M. J., S. M. Kingsman \& A. J. KingsMAN: Sequence variation in the LEU 2 region of the Saccharomyces cerevisiae genome. Gene 16, 133139 (1981)

11. Fink, G. R.: A cluster of genes controlling three enzymes in histidine biosynthesis in Saccharomyces cerevisiae. Genetics 53, 445-459 (1966)

12. HANSEN, E. Chr.: Recherches sur la physiologie et la morphologie des ferments alcooliques. Compt. Rend Lab. Carlsberg 7, 179-217 (1908)

13. Holmberg, S., J. G. L. Petersen, T. NilssonTillgRen \& M. C. Kielland-BrandT: Molecular characterization of a Saccharomyces plasmid containing the HIS4 gene. Carlsberg Res. Commun. 44, 269-282 (1979)

14. Holmberg, S., M,C. Kielland-Brandt, T. Nilsson-Tillgren \& J. G. L. Petersen: Molecular characterization of three his 4 deletion mutants in Saccharomyces cerevisiae. Carlsberg Res. Commun. 44, 283-288 (1979)

15. HolmberG, S.: Genetic differences between Saccharomyces carlsbergensis and S. cerevisiae. II. Restriction endonuclease analysis of genes in chromosome III. Carlsberg Res. Commun. 47, 233-244 (1982)

16. HolmES, D. S. \& M. QUiGLEY: A rapid boiling method for the preparation of bacterial plasmids. Anal. Biochem. 114, 193-197 (1981)

17. JefFreYs, A. J.\&R. A. FlaVell: A physical map of the DNA regions flanking the rabbit $\beta$-globin gene. Cell 12, 429-439 (1977)

18. Kielland-Brandt, M. C., T. Nilsson-Tillgren, S. Holmberg, J. G. L. Petersen, \& B. A. SVENNINGSEN: Transformation of yeast without use of foreign DNA. Carlsberg Res. Commun. 44, 77-87 (1979)

19. Maniatis, T., E. F. Fritsch \& J. Sambrook: Molecular cloning. A laboratory Manual. Cold Spring Harbor Laboratory, New York (1982)

20. Nilsson-Tillgren, T., J. G. L. Petersen, S. HOLMBERG \& M. C. KIELLAND-BRANDT: Transfer of chromosome III during kar mediated cytoduction in yeast. Carlsberg Res. Commun. 45, 113-117 (1980)

21. Nilsson-Tillgren, T., C. Guermansen, M. C. Kielland-Brandt, J.G. L. Petersen, \& S. HolmBERG: Genetic differences between Saccharomyces carlsbergensis and $\mathbf{S}$. cerevisiae. Analysis of chromosome III by single chromosome transfer. Carlsberg Res. Commun. 46, 65-76 (1981)

22. Nilsson-Tillgren. T., M. C. KiellandBrandt, S. Holmberg, J. G. L. Petersen \& C. GJERMANSEN: Is lager yeast a species hybrid?
Utilization of intrinsic genetic variation in breeding. Proc. IV Symp. Genet. Industrial Organisms, 143-147 (1982)

23. Pedersen, M. B.: Fingerprinting of DNA in the identification of yeast. Proc. 19th Europ. Brewery Conv. Congr. London, pp. 457-463 (1983)

24. Pedersen, M. B.: DNA sequence polymorphisms in the genus Saccharomyces I. Comparison of the HIS4 and ribosomal RNA genes in lager strains, ale strains and various species. Carlsberg Res. Commun. 48, 485-503 (1983)

25. Pedersen, M. B.: Brewing yeast identification by DNA fingerprinting. Proc. 20th Europ. Brewery Conv. Congr. Helsinki (1985)

26. Pedersen, M. B.: DNA sequence polymorphisms in the genus Saccharomyces II. Analysis of the genes RDN1, HIS4, LEU2 and Ty transposable elements in Carlsberg, Tuborg and 22 Bavarian brewing strains. Carlsberg Res. Commun. 50, 263272 (1985)

27. Pedersen, M. B.: DNA sequence polymorphisms in the genus Saccharomyces III. Restriction endonuclease fragment patterns of chromosomal regions in brewing and other yeast strains. Carlsberg Res. Commun. 51, 163-183 (1986)

28. Price, C. W., G. B. Fuson \& H. J. Phaff: Genome comparison in yeast systematics: Delimitation of species within the genera: Schwanniomyces, Saccharomyces, Debariomyces and Pichia. Microbiol. Rev. 42, 161-193 (1978)

29. Rigby, P. W. J., M. DieckmanN, C. Rhodes \& P. BERG: Labeling deoxyribonucleic acid to high specific activity in vitro by nick translation with DNA polymerase I. J. Mol. Biol. 113, 237-251 (1977)

30. Rosini, G., F. Federici, A. E. VAughan \& A. MarTINI: Systematics of the species of the genus Saccharomyces associated with the fermentation industry. European J. Appl. Microbiol. Biotechnol. 15, 188-193 (1982)

31. SChwarTZ, D. C \& C. R. CANTOR: Separation of yeast chromosome-sized DNAs by pulsed field gradient gel electrophoresis. Cell 37, 67-75 (1984)

32. Sherman, F., G. R. Fink \& J.R. Hicks: Methods in Yeast Genetics. Cold Spring Harbor Laboratory, Cold Spring Harbor, N. Y. 1 1724, pp. 61-64 (1979)

33. SOUTHERn, E. M.: Detection of specific sequences among DNA fragments separated by gel electrophoresis. J. Mol. Biol. 98, 503-517 (1975)

34. Storms, R. K., J.B. MCNeIL.P.S. Khandekar.G. AN, J. PARKer \& J. D. FrIesen: Chimeric plasmids for cloning of deoxyribonucleic acid sequences in Saccharomyces cerevisiae. J. Bacteriol. 140, 73-82 (1979)

35. WALt, J. P. van DER: Genus Saccharomyces, In: 
The Yeasts, a Taxonomic Study. J. Lodder, ed. North-Holland Publishing Company. Amstedam London pp. 555-718 (1970)

36. Wettstein, D. von: Emil Christian Hansen Centennial Lecture: from pure yeast culture to genetic engineering of brewers yeast. Proc. 19th Europ. Brewery Conv. Congr. London, pp. 97-120 (1983)

37. Wettstein, D. von, C. GJermansen. S. Holmberg. M. C. Kielland-Brandt. T. Nilsson. Tillgren. M. B. Pedersen. J.G. L. Petersen \& P. SIGSGAARD: Genetic engeneering in the improve- ment of brewers yeast. MBAA Tech. Quart. 21, 45-61 (1984)

38. WiNGE. Ø.\& O. LAUSTSEN: On 14 new yeast types. produced by hybridization. Compt. Rend. Lab. Carlsberg, Ser. Physiol. 22, 337-352 (1939)

39. YANG, C. A., J. LIS \& R. WU: Elution of DNA from agarose gels after electrophoresis. Meth. in Enzymol. 68, 176-182 (1979)

40. YARROW, D. \& T. NAKASE: DNA base composition of species of the genus Saccharomyces. Antonie van Leeuwenhoek 41, 81-88 (1975)

Accepted by E. LuND 